Research Article

\title{
Comparison of Asphalt Mixtures Designed Using the Marshall and Improved GTM Methods
}

\author{
Jianbing Lv $\mathbb{D}^{1}{ }^{1}$ Xu Zhancheng, ${ }^{1}$ Yin Yingmei, ${ }^{1}$ Zhang Jiantong, ${ }^{1}$ Sun Xiaolong, \\ and $\mathrm{Wu}$ Chuanhai ${ }^{2}$ \\ ${ }^{1}$ Guangdong University of Technology, Guangzhou 510006, Guangdong, China \\ ${ }^{2}$ Guangdong Hualu Traffic Technology Co. Ltd, Guangzhou 510006, Guangdong, China
}

Correspondence should be addressed to Jianbing Lv; ljbzh@126.com

Received 9 June 2018; Accepted 16 September 2018; Published 1 November 2018

Guest Editor: Ghazi G. Al-Khateeb

Copyright (c) 2018 Jianbing Lv et al. This is an open access article distributed under the Creative Commons Attribution License, which permits unrestricted use, distribution, and reproduction in any medium, provided the original work is properly cited.

\begin{abstract}
The Marshall method is today considered the standard method of asphalt mixture design for practical engineering applications. By using this method, engineering designers reap the benefits of its easy implementation and inexpensive equipment requirements. However, the Marshall method also has shortcomings and limitations, such as the difficulty in simulating the actual working conditions of a road under heavy load. Therefore, it is desirable to develop alternative methods for designing asphalt mixtures that can simulate the actual conditions under which the road will be used and so enable technically superior road construction. The emergence of the gyratory testing machine (GTM) method represents a new direction in asphalt mixture design that could plan more effectively for heavy loads in a hot and humid environment. In this paper, the two design methods are compared on the basis of the oil-stone ratio, high-temperature stability, water stability, and rutting resistance of the mixes they recommend. We put forward an improved GTM method suitable for the high temperatures and heavy traffic in Guangdong Province. This work provides a foundation for the large-scale popularization and application of the GTM method.
\end{abstract}

\section{Introduction}

The premature destruction of asphalt pavement in highgrade Chinese highways mainly occurs through the formation of grooves, oil pan, and water damage. Studies have shown that these early failure phenomena are attributable to a high asphalt content, the low density of the mixture, the degree of compaction, high porosity, or poor gradation [1-4]. At present, the most commonly used asphalt mixture design methods are the Marshall method, the Wim method, the superpave volume method, and the gyratory testing machine (GTM) method. The formation process with the GTM method simulates the actual conditions experienced by the road, enabling the design of an asphalt mixture with good antirutting performance. Due to this major advantage, GTM is gaining increasing attention in national road engineering circles [5-10].

At present, asphalt mixtures designed using the Marshall method cannot control the density of the final specimen formed, which means that the porosity cannot be adequately controlled. In theory, GTM design takes the final density of the pavement mixture as a design constraint. This significantly remedies some of the flaws inherent in the Marshall design method. The early GTM design method was mainly aimed at preventing the deformation of the rut and did not pay special attention to the durability, aging resistance, and fatigue resistance of the pavement structure. And the GTM method has not proposed a special method for the selection of aggregate gradation; hence, only the traditional grading specifications and determining methods were used (used in the Marshall design method). In addition, it is still controversial for how to use GSI and GSF indicators to determine the best asphalt ratio of asphalt mixtures. Therefore, the early GTM design method is necessary to be improved.

The density of a GTM-designed asphalt mixture at equilibrium is determined by instrumental parameters such as the machine angle, vertical pressure, and test temperature. However, it can be challenging to determine 
the optimal oil-stone ratio for the GTM method due to a lack of consensus as to the appropriate gyratory stability index (GSI), with some scholars advocating for using a GSI of 1 , and others, a GSI of 1.03. Additionally, the performance of mixtures designed using the GTM method is not demonstrably superior, indicating that the method still needs improvement.

\section{A Comparative Analysis of the Improved GTM and Marshall Methods}

\subsection{Selection of Raw Materials}

2.1.1. Selection of Asphalt and Minerals. The asphalt used in this study is Grade A No. 70 asphalt produced by the China National Petroleum Company (CNPC). Its technical indicators are in accordance with the requirements of current Chinese regulations [11] (Table 1). The coarse aggregate is granite gravel produced by Qingyuan (stone specifications: 11-22 mm, 11-16 mm, 6-11 mm, and 3-6 mm), and fine aggregates are granite produced by Qingyuan. The filler is ground limestone produced by Conghua, and the antistripping agent is a cement produced in Pingtang Town. Its technical indicators are in accordance with the requirements of current Chinese regulations [11] (Table 2). To minimize variability in the test data, the aggregates were washed and sieved and then backmatched.

2.1.2. Selection of Mineral Aggregate Gradations. GTM rotary compaction and Marshall compaction tests were carried out on four kinds of AC-16-type asphalt mixtures commonly used in Guangdong Province. The high-temperature stability and water stability of the mixes produced using the two methods were compared and analyzed. The gradations of the mineral aggregate tested are listed in Table 3.

2.2. Determination of the Best Oil-Stone Ratio Using the Marshall Method. Marshall asphalt mixture tests were carried out according to the current standard practice in China, being compacted 75 times on both sides at a compaction temperature of $140^{\circ} \mathrm{C}-150^{\circ} \mathrm{C}$. The best oil-stone ratios for each gradation were determined by plotting the data and are shown in Table 4. Both light and heavy traffic were considered in determining the optimum oil-stone ratio, for which design porosities of $4.0 \%$ and $5.0 \%$, respectively, were adopted.

Table 4 indicates the following:

(1) The characteristics of gradations 1 and 2 are very similar to each other and are consistent with past experience; gradations 3 and 4 also show very similar characteristics to each other but differ significantly from 1 and 2 . It is necessary to use a higher proportion of asphalt to achieve the same porosity for gradations 3 and 4 .

(2) The VMA (voids in mineral aggregate, calculated by theoretical maximum relative) with the best oil-stone ratio for gradations 1 and 2 does not meet the requirements of the specification [11]. To meet the requirements, the porosity would need to be reduced to $3.5 \%$, significantly increasing the amount of asphalt required.

(3) New technical specifications for asphalt pavement construction have recently been published [11]. Because the absorbency of asphalt is taken into account in the calculation of mineral aggregate porosity, the calculated VMA is $\sim 1-2 \%$ lower than that with the previous method. This has rendered it the most difficult requirement to meet in gradation design. For the materials used in this case, the composition of gradations 1 and 2 should be adjusted according to the actual materials that would be used. Adjusting the size of the gradation is the simplest way to make the indicators of the Marshall test meet the requirements.

(4) When designing for heavy traffic, the best oil-stone ratio of AC-16 asphalt was reduced by $0.3-0.5 \%$. However, only the porosity and not the saturation and mineral aggregate gap met the requirements [12].

\subsection{Improved Optimal Design of the Oil-Stone Ratio Using the} GTM Method. In the GTM test, each asphalt mixture was molded according to ASTM D3387. The rotation parameters were set to a vertical pressure of $0.7 \mathrm{MPa}$ and a machine angle of $0.8^{\circ}$ (oil pressure gauge); the specimen model was controlled as a limit equilibrium. The sample diameter was set at $101.6 \mathrm{~mm}$ and the mold temperature at $60^{\circ} \mathrm{C}$, and the initial temperature of compaction was $140-150^{\circ} \mathrm{C}$. The test results are shown in Figures 1-6.

Figures 1-6 indicate that the gyratory shear factor (GSF) of the asphalt mixtures tested is greater than 1.3 and the rotation stability coefficient, GSI, is less than 1.05 . It is not, however, possible to meet the requirements of the design [11] (Table 5) using either the initial GTM design method (when the gyratory stability index, GSI, is close to 1.0 , the corresponding amount of asphalt is the maximum amount of asphalt in the mixture, and when the GSF of the mixture is greater than 1.0, the mixture density reaches the maximum value) or the results of relevant research (GSI $=1.05$, oilstone ratio for GSF $>1.3$ ) as the best asphalt mix dosage standards.

It is therefore necessary to find an alternative method for determining the optimum amount of asphalt for the GTM mixture. We have devised an improved GTM asphalt mixture design methodology for selecting the best oil-stone ratio, as follows:

(1) As in Figures 1-6, data are plotted using the oil-stone ratio or weight of asphalt as the abscissa and the volume index and mechanical indicators of the GTM specimens on the vertical axis. A smooth curve is plotted to fit the results.

(2) Firstly, the asphalt dosage range $\mathrm{OAC}_{\min }-\mathrm{OAC}_{\max }$ (OAC $=$ optimum asphalt content) that would meet the technical standards for GTM design of an asphalt 
TABle 1: No. 70 asphalt test results.

\begin{tabular}{|c|c|c|c|}
\hline Test & Method & Specified value & Measured value \\
\hline \multirow{3}{*}{ Penetration $(0.1 \mathrm{~mm})$} & $25^{\circ} \mathrm{C}, 100 \mathrm{~g}, 5 \mathrm{~s}$ & $60-80$ & 61 \\
\hline & $15^{\circ} \mathrm{C}, 100 \mathrm{~g}, 5 \mathrm{~s}$ & - & 20 \\
\hline & $30^{\circ} \mathrm{C}, 100 \mathrm{~g}, 5 \mathrm{~s}$ & - & 113 \\
\hline Penetration index (PI) & - & -1.5 to +1.0 & -1.42 \\
\hline \multirow{2}{*}{ Ductility $(\mathrm{cm})$} & $5 \mathrm{~cm} / \mathrm{min}, 15^{\circ} \mathrm{C}$ & $\nless 100$ & $>100$ \\
\hline & $5 \mathrm{~cm} / \mathrm{min}, 10^{\circ} \mathrm{C}$ & $\nless 15$ & $>100$ \\
\hline Softening point $\left({ }^{\circ} \mathrm{C}\right)$ & Ring and ball method & $\nless 46$ & 47.0 \\
\hline Dynamic viscosity $(\mathrm{Pa} \cdot \mathrm{s})$ & $60^{\circ} \mathrm{C}$ & $\nless 180$ & 191.9 \\
\hline Kinematic viscosity $(\mathrm{Pa} \cdot \mathrm{s})$ & $135^{\circ} \mathrm{C}$ & - & 0.365 \\
\hline
\end{tabular}

TABLE 2: Aggregate physical and mechanical indicators.

\begin{tabular}{|c|c|c|c|c|c|c|}
\hline \multirow[b]{2}{*}{ Material name } & \multicolumn{6}{|c|}{ Test project } \\
\hline & $\begin{array}{l}\text { Apparent relative } \\
\text { density }\left(\mathrm{g} / \mathrm{cm}^{3}\right)\end{array}$ & $\begin{array}{l}\text { Gross volume relative } \\
\text { density }\left(\mathrm{g} / \mathrm{cm}^{3}\right)\end{array}$ & $\begin{array}{c}\text { Needle particle } \\
\text { content }(\%)\end{array}$ & $\begin{array}{l}\text { Crushing } \\
\text { value }(\%)\end{array}$ & $\begin{array}{c}<0.075 \text { particle } \\
\text { content }(\%)\end{array}$ & $\begin{array}{c}\text { Water } \\
\text { absorption (\%) }\end{array}$ \\
\hline $11-22 \mathrm{~mm}$ gravel & 2.740 & 2.699 & 5.5 & - & 0.3 & 0.56 \\
\hline $11-16 \mathrm{~mm}$ gravel & 2.744 & 2.701 & 4.8 & 11.7 & 0.2 & 0.63 \\
\hline 6-11 mm gravel & 2.752 & 2.692 & - & - & 0.4 & 0.82 \\
\hline $3-6 \mathrm{~mm}$ gravel $(\geq 2.36 \mathrm{~mm})$ & 2.726 & 2.652 & - & - & & 1.02 \\
\hline $3-6 \mathrm{~mm}$ gravel $(<2.36 \mathrm{~mm})$ & 2.705 & 2.644 & - & - & 2.1 & 0.96 \\
\hline $0-3 \mathrm{~mm}$ gravel $(\geq 2.36 \mathrm{~mm})$ & 2.725 & 2.639 & - & - & & 1.21 \\
\hline $0-3 \mathrm{~mm}$ gravel $(<2.36 \mathrm{~mm})$ & 2.714 & 2.639 & - & - & 4.8 & 1.06 \\
\hline Filler & 2.784 & - & - & - & - & - \\
\hline Cement & 3.099 & - & - & - & - & - \\
\hline
\end{tabular}

TABLE 3: Selected AC-16 asphalt mixture design gradations.

\begin{tabular}{lcccccccccccc}
\hline \multirow{2}{*}{ Gradation number } & \multicolumn{10}{c}{ Sieve hole $(\mathrm{mm})$ pass rate (\%) } \\
& 26.5 & 19 & 16 & 13.2 & 9.5 & 4.75 & 2.36 & 1.18 & 0.6 & 0.3 & 0.15 & 0.075 \\
\hline 1 & 100 & 100 & 95.0 & 80.0 & 60.0 & 40.0 & 29.5 & 22.0 & 17.5 & 13.0 & 9.5 & 6.5 \\
2 & 100 & 100 & 97.5 & 80.0 & 60.0 & 35.0 & 26.5 & 22.0 & 17.5 & 13.0 & 9.5 & 6.5 \\
3 & 100 & 100 & 97.5 & 82.5 & 68.0 & 52.5 & 41.0 & 29.5 & 22.0 & 16.0 & 11.0 & 6.0 \\
4 & 100 & 100 & 97.3 & 78.5 & 56.9 & 30.0 & 23.0 & 19.3 & 15.6 & 11.9 & 9.0 & 6.5 \\
\hline
\end{tabular}

TABLE 4: Summary of the oil-stone ratios for asphalt mixtures selected using the Marshall method.

\begin{tabular}{|c|c|c|c|c|c|c|c|c|c|}
\hline & $\begin{array}{l}\text { Gradation } \\
\text { number }\end{array}$ & $\begin{array}{l}\text { Selected } \\
\text { oil-stone } \\
\text { ratio (\%) }\end{array}$ & $\begin{array}{l}\text { Theoretical } \\
\text { maximum } \\
\text { relative } \\
\text { density }\left(\mathrm{g} / \mathrm{cm}^{3}\right)\end{array}$ & $\begin{array}{c}\text { Measured } \\
\text { density }\left(\mathrm{g} / \mathrm{cm}^{3}\right)\end{array}$ & $\begin{array}{l}\text { Porosity } \\
\text { (\%) }\end{array}$ & $\begin{array}{l}\text { Mineral material } \\
\text { clearance rate }(\%)\end{array}$ & $\begin{array}{l}\text { Saturation } \\
\quad(\%)\end{array}$ & $\begin{array}{c}\text { Marshall } \\
\text { stability }(\mathrm{kN})\end{array}$ & $\begin{array}{c}\text { Flow } \\
\text { value }(0.1 \mathrm{~mm})\end{array}$ \\
\hline \multirow{2}{*}{1} & Light load & 4.47 & 2.502 & 2.401 & 4.0 & 13.0 & 68.9 & 13.05 & 35.0 \\
\hline & Overload & 4.17 & 2.512 & 2.387 & 5.0 & 13.2 & 62.3 & 13.20 & 33.5 \\
\hline \multirow{2}{*}{2} & Light load & 4.56 & 2.504 & 2.405 & 4.0 & 13.0 & 69.6 & 11.70 & 33.0 \\
\hline & Overload & 4.15 & 2.518 & 2.391 & 5.0 & 13.1 & 61.5 & 12.50 & 28.0 \\
\hline \multirow{2}{*}{3} & Light load & 4.84 & 2.488 & 2.388 & 4.0 & 13.5 & 70.2 & 13.30 & 23.9 \\
\hline & Overload & 4.50 & 2.499 & 2.374 & 5.0 & 13.7 & 63.5 & 14.80 & 24.4 \\
\hline \multirow{2}{*}{4} & Light load & 4.98 & 2.488 & 2.388 & 4.0 & 14.0 & 71.3 & 9.60 & 34.9 \\
\hline & Overload & 4.60 & 2.501 & 2.375 & 5.0 & 14.2 & 64.5 & 9.70 & 34.9 \\
\hline
\end{tabular}




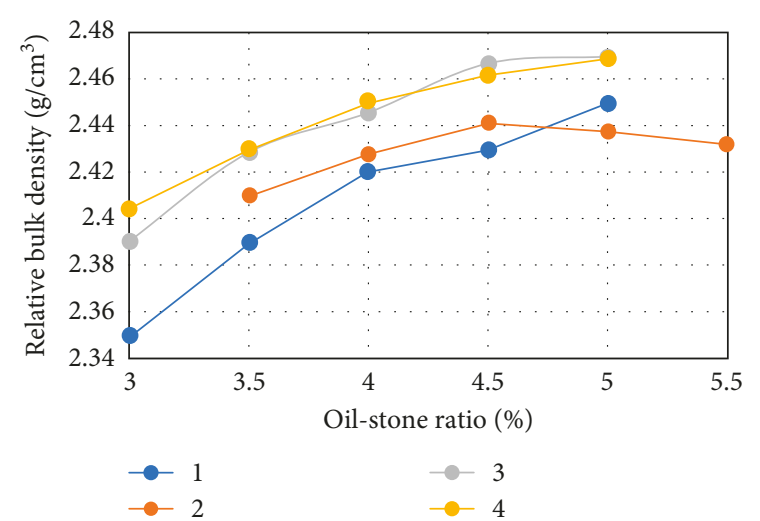

FIGURE 1: Relation between AC-16 relative bulk density and oilstone ratio.

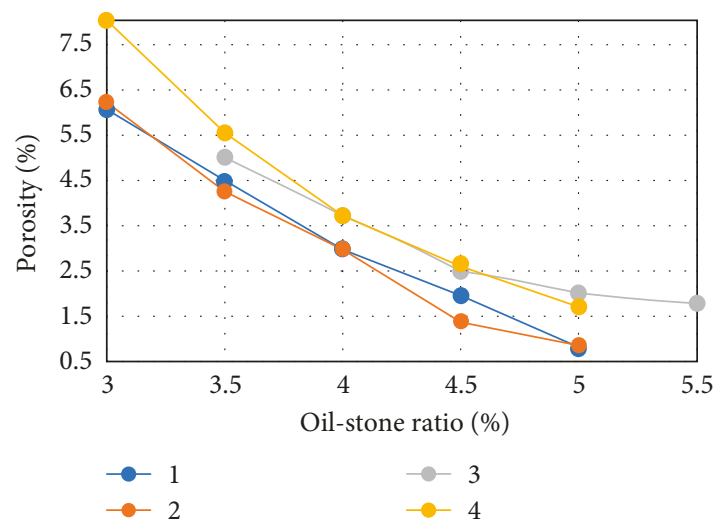

FIgURE 2: Relation between AC-16 porosity and oil-stone ratio.

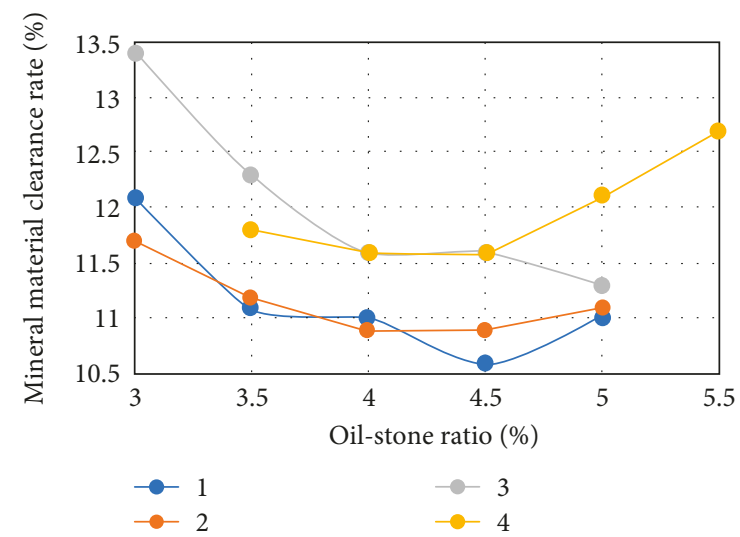

FIGURE 3: Relation between AC-16 mineral material clearance rate and oil-stone ratio.

mixture (Table 5) is determined. The selected range of bitumen usage must cover the full range of porosity. Furthermore, it should cover as much of the range in the asphalt saturation requirements as possible and produce a peaked GSF curve. If the full range of design porosity is not covered, the test must be repeated.

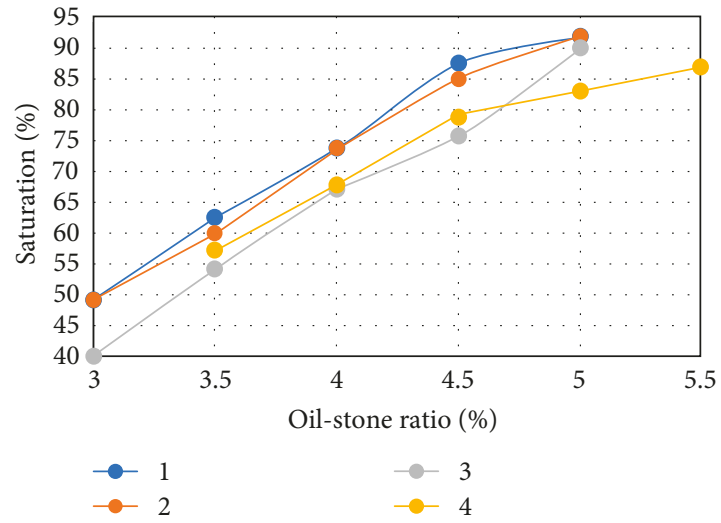

FIGURE 4: Relation between AC-16 saturation and oil-stone ratio.



FIgURE 5: Relation between AC-16 shear safety factor and oil-stone ratio.

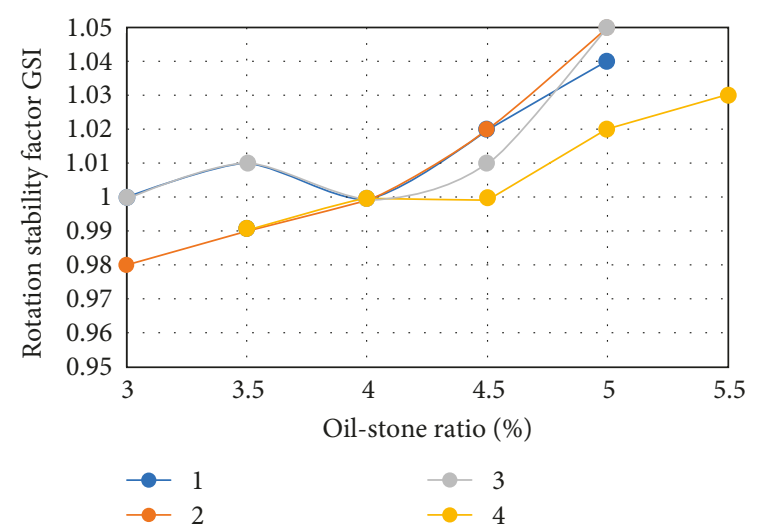

FIgURE 6: Relation between AC-16 rotation stability factor and oilstone.

(3) The maximum density, $a_{1}$, the maximum shear safety factor GSF, $a_{2}$, the target void fraction (or median), $a_{3}$, and the asphalt dosage, $a_{4}$, in the asphalt saturation range are taken from the curves. If the range of asphalt used in the test fails to cover the required range of asphalt saturation, the average value of $a_{1}$, $a_{2}$, and $a_{3}$ is taken as $\mathrm{OAC}_{1}$. If the GSF or the density 
TABLE 5: Technical standards for an asphalt mixture designed by the GTM method (0.7 Mpa).

\begin{tabular}{|c|c|}
\hline Pilot projects & Technical indicators \\
\hline Dimensions of the specimen $(\mathrm{mm})$ & $101.6 \times 100$ \\
\hline Standard density & $\begin{array}{l}\text { GTM final density } \\
\text { about rotational } \\
\text { compaction }\end{array}$ \\
\hline Porosity (\%) & $2.0 \sim 4.0$ \\
\hline Saturation VFA (\%) & $60 \sim 80$ \\
\hline Rotation stability GSI & $\ngtr 1.05$ \\
\hline Shear stability GSF & $\nless 1.30$ \\
\hline \multicolumn{2}{|c|}{$\begin{array}{l}\text { The minimum VMA requirement corresponding to the nominal } \\
\text { particle size }(\mathrm{mm})\end{array}$} \\
\hline Nominal particle size $(\mathrm{mm})$ & $\begin{array}{llll}26.5 & 19.0 & 16.0 & 13.2\end{array}$ \\
\hline Mineral material clearance rate VMA (\%) & $\begin{array}{llll}10.0 & 10.0 & 10.5 & 11.0\end{array}$ \\
\hline
\end{tabular}

does not reach a peak value, we take the goal porosity corresponding to bitumen quantity $a_{3}$ as $\mathrm{OAC}_{1}$. $\mathrm{OAC}_{1}$ must be in the range $\mathrm{OAC}_{\min }-\mathrm{OAC}_{\max }$, or else the design should be remixed.

(4) The median value of $\mathrm{OAC}_{\min }-\mathrm{OAC}$ max with indicators in line with technical standards (excluding VMA) is used for $\mathrm{OAC}_{2}$.

(5) The median of $\mathrm{OAC}_{1}$ and $\mathrm{OAC}_{2}$ is used as the best asphalt OAC.

(6) On the basis of the optimum amount of asphalt, we determine the voidage and check whether the VMA meets the technical requirements.

Applying this improved GTM design methodology to the experimental results shown in Figures 1-6, we determined the best oil-stone ratio for each gradation (Table 6).

\subsection{Contrastive Analysis of the Two Design Methods}

(1) For an asphalt mixture with the same proportions, the GTM specimen density was $1.52-3.36 \%$ higher than that from the Marshall method (Table 7). The percentage density increase varies with gradation and also differs for different oil-stone ratios at the same gradation level. The density decreases with an increase in the asphalt content.

(2) Changes in the density, porosity, and mineral void ratio of GTM specimens with a change in the oilstone ratio are similar to those observed with the Marshall method. When the oil-stone ratio is identical, the porosity and mineral aggregate clearance rate in asphalt concrete designed by GTM are much lower than in that designed with the Marshall method. This is advantageous for the stability and durability of the road.

(3) With a change in the oil-stone ratio, the change in GTM GSF is similar to that of Marshall, and there is a peak or abrupt change point. The GSF can be used as an indicator of shear strength. It can also be used to evaluate the sensitivity of gradation shear strength to variation in the mass ratio. When the GSF for asphalt changes slowly, it can be considered that the shear strength is less sensitive to the amount of asphalt. Asphalt has better high-temperature performance when the GSF for asphalt changes slowly.

(4) The asphalt content that would be selected on the basis of the Marshall method is higher than the maximum quantity determined with the GTM method at $0.7 \mathrm{MPa}$ pressure. This may lead to rutting and the emergence of oil pan. Even when using the heavy traffic standard in the Marshall method, this problem is not fundamentally resolved. Additionally, the increased porosity would lead to poor water stability, and the degree of compaction would need to be increased to $99 \%$.

\section{Performance Test of an Antirutting Asphalt Mixture Designed with the GTM Method}

3.1. High-Temperature Stability. To evaluate the hightemperature stability of the asphalt concrete, a rutting test was performed, applying JTJ052-2000 regulations [13]. Specimens measuring $300 \mathrm{~mm} \times 300 \mathrm{~mm} \times 50 \mathrm{~mm}$ and with $100 \%$ compaction were used. The density of the Marshall and GTM specimens were used as the standard density. The test results are shown in Table 8.

Table 7 indicates the following:

(1) The dynamic stability of different gradations does not increase monotonously with an increase in coarse aggregate content $[2,14]$; indeed, extremely high gradation may have a negative impact on hightemperature stability. When using the heavy traffic variation of the Marshall method, the dynamic stability of the rutting test improves [15-17].

(2) A mixture designed using GTM shows better dynamic stability than the one designed using Marshall and in some cases meets the requirements of a modified asphalt mixture. In addition, GTMdesigned mixtures show lower relative deformation than Marshall-designed mixtures.

(3) Asphalt mixtures of the same grade may have different high-temperature properties under the two methods. Of the four selected AC-16 mixes, gradation 4's high-temperature performance was the worst under the Marshall method but the best with GTM.

3.2. Water Stability. For evaluating the water stability of asphalt mixtures, the Lottman freeze-thaw splitting method currently shows the best correlation with the behavior of actual road surfaces $[11,18]$. Therefore, GTM and Marshall mixtures were tested for water stability using this method. The results of this analysis indicate the following:

(1) The splitting strength indicates that a mixture designed using the GTM method is significantly more resilient than the one designed using the Marshall method: the splitting strength of AC16 was 
TABLE 6: Summary table of the optimal oil-stone ratio for selected asphalt mixtures according to the GTM method.

\begin{tabular}{|c|c|c|c|c|c|c|c|c|}
\hline $\begin{array}{l}\text { Gradation } \\
\text { number }\end{array}$ & $\begin{array}{l}\text { Selected } \\
\text { oil-stone } \\
\text { ratio (\%) } \\
\end{array}$ & $\begin{array}{c}\text { Theoretical } \\
\text { maximum relative } \\
\text { density }\left(\mathrm{g} / \mathrm{cm}^{3}\right)\end{array}$ & $\begin{array}{c}\text { Measured } \\
\text { density }\left(\mathrm{g} / \mathrm{cm}^{3}\right)\end{array}$ & $\begin{array}{l}\text { Porosity } \\
(\%)\end{array}$ & $\begin{array}{l}\text { Mineral material } \\
\text { clearance rate }(\%)\end{array}$ & $\begin{array}{l}\text { Saturation } \\
\quad(\%)\end{array}$ & $\begin{array}{l}\text { Shear safety } \\
\text { factor GSF }\end{array}$ & $\begin{array}{c}\text { Rotation } \\
\text { stability } \\
\text { factor GSI }\end{array}$ \\
\hline 1 & 4.1 & 2.520 & 2.454 & 2.6 & 10.8 & 75.7 & 1.91 & 1.00 \\
\hline 2 & 4.0 & 2.518 & 2.445 & 2.9 & 11.0 & 73.6 & 1.93 & 1.00 \\
\hline 3 & 4.2 & 2.507 & 2.426 & 3.2 & 11.6 & 72.1 & 1.85 & 1.00 \\
\hline 4 & 4.3 & 2.511 & 2.436 & 2.9 & 11.6 & 74.2 & 1.89 & 1.00 \\
\hline
\end{tabular}

TABle 7: Difference in bulk density for the two methods of asphalt mixture design.

Percentage increase of GTM forming density relative to Marshall compaction in different asphalt ratios (\%)

Gradation number

Oil-stone ratio

\begin{tabular}{lccccc} 
& 3.5 & 4.0 & 4.5 & 5.0 & \\
\hline 1 & 3.36 & 2.64 & 2.62 & 1.52 & 2.15 \\
2 & 2.75 & 2.60 & 2.46 & 2.59 & 2.49 \\
3 & 2.84 & 3.33 & 2.40 & 2.05 & 2.79 \\
4 & 2.60 & 2.88 & 2.87 & 2.60 \\
Average & 2.89 & 2.86 & 2.59 & 2.08 & 2.60 \\
\hline
\end{tabular}

TABLE 8: Results of a rutting test on the selected asphalt mixtures.

\begin{tabular}{|c|c|c|c|c|c|c|}
\hline Gradation number & \multicolumn{2}{|c|}{ Design method } & $\begin{array}{c}\text { Test temperature } \\
\left({ }^{\circ} \mathrm{C}\right)\end{array}$ & $\begin{array}{c}\text { Test } \\
\text { pressure }(\mathrm{MPa}) \\
\end{array}$ & $\begin{array}{c}\text { Dynamic } \\
\text { stability }(\mathrm{mm} / \text { time }) \\
\end{array}$ & Deformation rate $(\%)$ \\
\hline \multirow{3}{*}{1} & \multirow{3}{*}{$\begin{array}{l}\text { Marshall method } \\
\text { GTM method }\end{array}$} & Light load & 60 & 0.7 & 1512 & 8.0 \\
\hline & & Overload & 60 & 0.7 & 2080 & 8.4 \\
\hline & & $0.7 \mathrm{MPa}$ & 60 & 0.7 & 3315 & 5.2 \\
\hline \multirow{3}{*}{2} & \multirow{2}{*}{ Marshall method } & Light load & 60 & 0.7 & 1632 & 9.6 \\
\hline & & Overload & 60 & 0.7 & 2172 & 9.1 \\
\hline & GTM method & $0.7 \mathrm{MPa}$ & 60 & 0.7 & 3480 & 5.7 \\
\hline \multirow{3}{*}{3} & \multirow{3}{*}{$\begin{array}{c}\text { Marshall method } \\
\text { GTM method }\end{array}$} & Light load & 60 & 0.7 & 1690 & 8.1 \\
\hline & & Overload & 60 & 0.7 & 2356 & 8.4 \\
\hline & & $0.7 \mathrm{MPa}$ & 60 & 0.7 & 3320 & 5.0 \\
\hline \multirow{3}{*}{4} & \multirow{3}{*}{$\begin{array}{c}\text { Marshall method } \\
\text { GTM method }\end{array}$} & Light load & 60 & 0.7 & 828 & 10.8 \\
\hline & & Overload & 60 & 0.7 & 1940 & 9.6 \\
\hline & & $0.7 \mathrm{MPa}$ & 60 & 0.7 & 3753 & 5.6 \\
\hline
\end{tabular}

$24.6 \%$ higher before freezing and $31.1 \%$ higher after freezing.

(2) The freeze-thaw splitting residual strength ratio also indicates that a mixture designed using GTM is an improvement on the one designed using the Marshall method: it is, on average, 5.1\% higher for AC16type mixtures.

In summary, because of the differences in oil-stone ratio and void ratio between the mixtures designed by the two methods, they have significantly different degrees of water stability. It is generally believed that the water stability of the asphalt mixture is better when the oil-stone ratio is higher or the asphalt film is thicker.

\section{Conclusions}

(1) For asphalt mixtures with the same proportions, the density of a GTM specimen is $1.52-3.57 \%$ higher than that of a Marshall specimen. The amount of density increase varies with gradation. For a given gradation, the density decreases with an increase in the oil-stone ratio. Therefore, simply reducing the oil-stone ratio to adapt to heavy traffic conditions in the Marshall method has limited usefulness, as one cannot rely on a consistent relationship between the two variables to replicate the GTM method.

(2) When using the different methods, asphalt mixtures with the same gradation may have completely different high-temperature performance. Especially for coarsely graded mixtures, special measures must be taken to prevent the selection of asphalt with poor high-temperature performance, such as an appropriate increase in porosity or the use of GTM design.

(3) The GTM method simulates conditions in the field, and its design performance indices (final density, GSF, GSI, etc.) are directly linked to the mechanical 
parameters of the road. However, it abandons the use of the asphalt mixture volume index, which was the result of much practical experience. Its design performance indices are the result of theoretical reasoning, and there is still some debate as to the optimal values. Because of these issues, a valuable approach is to combine GTM mechanical design with traditional volume design and so benefit from the advantages of both. The antirutting performance of an asphalt mixture designed in this manner is improved over that of the one designed using the Marshall method, as is the water stability due to a reduction in the void fraction.

\section{Data Availability}

The data used to support the findings of this study are available from the corresponding author upon request.

\section{Conflicts of Interest}

The authors declare that they have no conflicts of interest.

\section{Acknowledgments}

This publication was supported by the National Natural Science Foundation of China Project (51508109 and 51608085). The authors would also like to thank all those who contributed to the experimental part of this study. And thanks are due to Guangdong Hualu Traffic Technology Co. Ltd. for providing some experimental equipment and also for the guidance of engineers Li Shanqiang and Fang Yang in the experimental side.

\section{References}

[1] A. I. Zhangfa, Structural Analysis and Performance Evaluation of Heavy-Duty Asphalt Pavement, Southwest Jiaotong University, Chengdu, China, 2002.

[2] $\mathrm{Z}$. $\mathrm{Li}$ and $\mathrm{D}$. Wu, "Design and research on the warm-mix rubber-modified asphalt mixture based on the GTM method," Advanced Materials Research, vol. 598, pp. 543-551, 2012.

[3] W. Zhou, Asphalt Pavement Engineering Handbook, China Communications Press, Beijing, China, 2003.

[4] D. Han, L. Wei, and J. Zhang, "Experimental study on performance of asphalt mixture designed by different method," Procedia Engineering, vol. 138, pp. 407-414, 2016.

[5] X. Feng and Z. Gao, "Comparative study on GTM method and marshall mixes design method for large stone asphalt mixes," in Proceedings of GeoHunan International Conference 2009, vol. 193, pp. 106-111, Changsha, Hunan, China, August 2009.

[6] P. Chakroborty, A. Das, and P. Ghosh, "Determining reliability of an asphalt mix design: case of marshall method," Journal of Transportation Engineering-ASCE, vol. 136, no. 1, pp. 31-37, 2010.

[7] R. Namli and N. Kuloglu, "Experimental comparison of superpave and marshall methods," Teknik Dergi, vol. 18, no. 2, pp. 4103-4118, 2007.

[8] S. D. Hwang and B. Kim, "Method mix design marshall mix design and comparative evaluation with current marshall mix design method," Journal of the Korean Society of Road Engineers, vol. 6, no. 4, pp. 13-24, 2004.
[9] L. J. Ma, J. Y. Zhang, and Z. Li, "The road-test of high performance asphalt mixture with superpave," Applied Mechanics and Materials, vol. 361-363, pp. 1576-1579, 2013.

[10] T. Fan, "Influence of mix proportion of asphalt mixture on marshall index," in Proceedings of International Conference on Electric Technology and Civil Engineering (ICETCE), pp. 5123-5127, Lushan, China, April 2011.

[11] Highway Research Institute of the Ministry of Communications, JTG F40-2004 Technical Specifications for Asphalt Pavement Construction, China Communications Press, Beijing, China, 2009.

[12] Y. Doh and K. Kim, "Volumetric property difference in mix design results by superpave and marshall method," Journal of the Korean Society of Road Engineers, vol. 6, no. 4, pp. 65-73, 2004.

[13] Ministry of Communications of the People's Republic of China, JTG F40-2004 Technical Code for Construction of Highway Asphalt Pavement, China Communications Press, Beijing, China, 2001.

[14] C. Wu and B. Tan, "Study on verification of evaluation indexes of shear resistance of asphalt mixtures based on GTM method," Advances of Transportation: Infrastructure and Materials, vol. 1, pp. 171-179, 2016.

[15] S. Saride, D. Avirneni, and S. C. P. Javvadi, "Utilization of reclaimed asphalt pavements in indian low-volume roads," Journal of Materials in Civil Engineering, vol. 28, no. 2, article 04015107, 2016.

[16] T. Xu and X. Huang, "Investigation into causes of in-place rutting in asphalt pavement," Construction and Building Materials, vol. 28, no. 1, pp. 525-530, 2012.

[17] P. Ayar, F. Moreno-Navarro, and M. C. Rubio-Gámez, "The healing capability of asphalt pavements: a state of the art review," Journal of Cleaner Production, vol. 113, pp. 28-40, 2016.

[18] J. Mills-Beale, Z. You, E. Fini et al., "Aging influence on rheology properties of petroleum-based asphalt modified with bio-binder," Journal of Materials in Civil Engineering, vol. 26, no. 2, pp. 358-366, 2014 


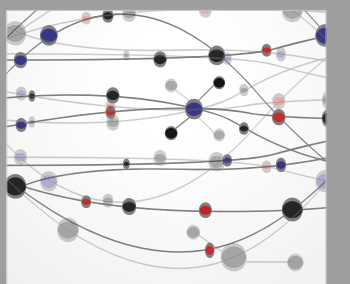

The Scientific World Journal
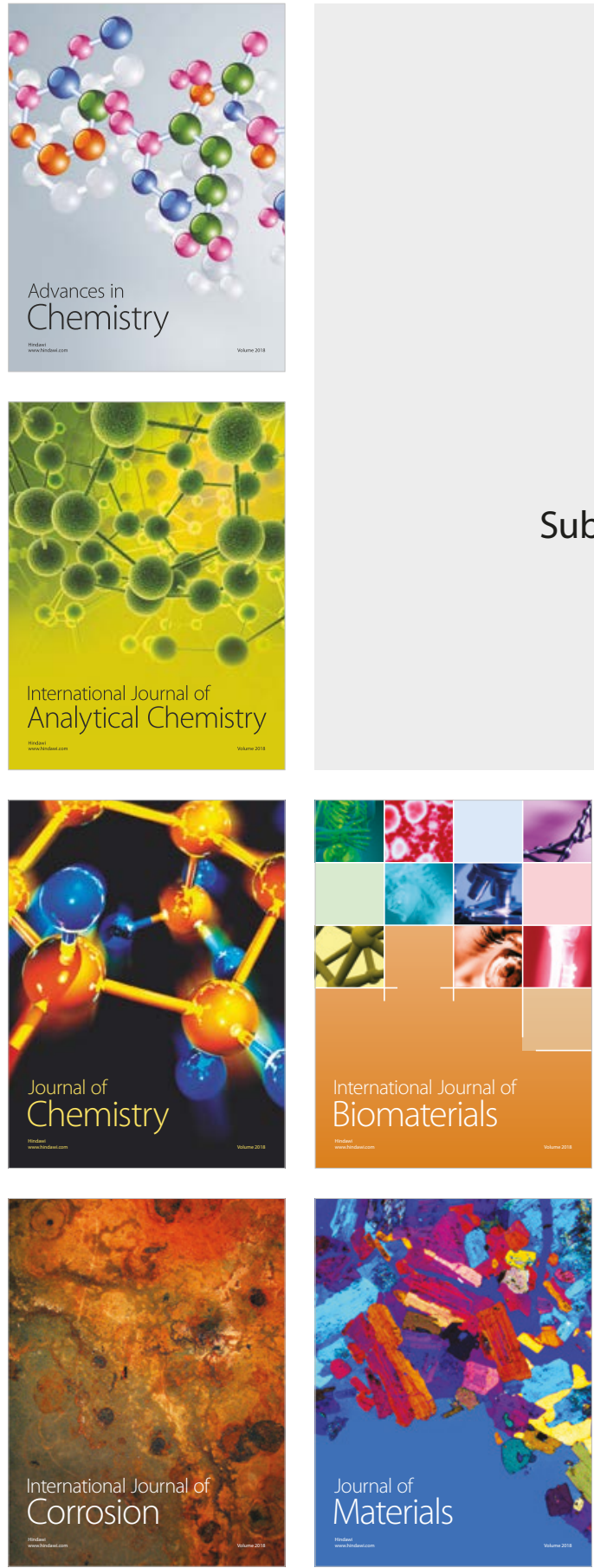

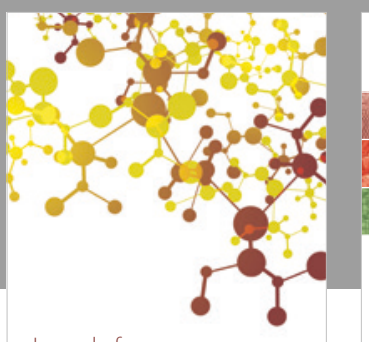

Journal of

Applied Chemistry
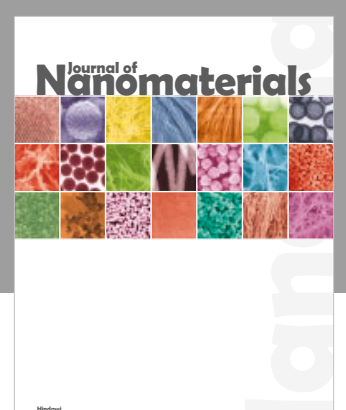



Scientifica



Polymer Science

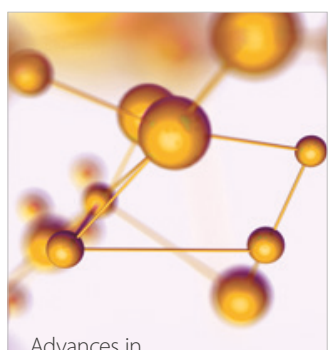

Physical Chemistry
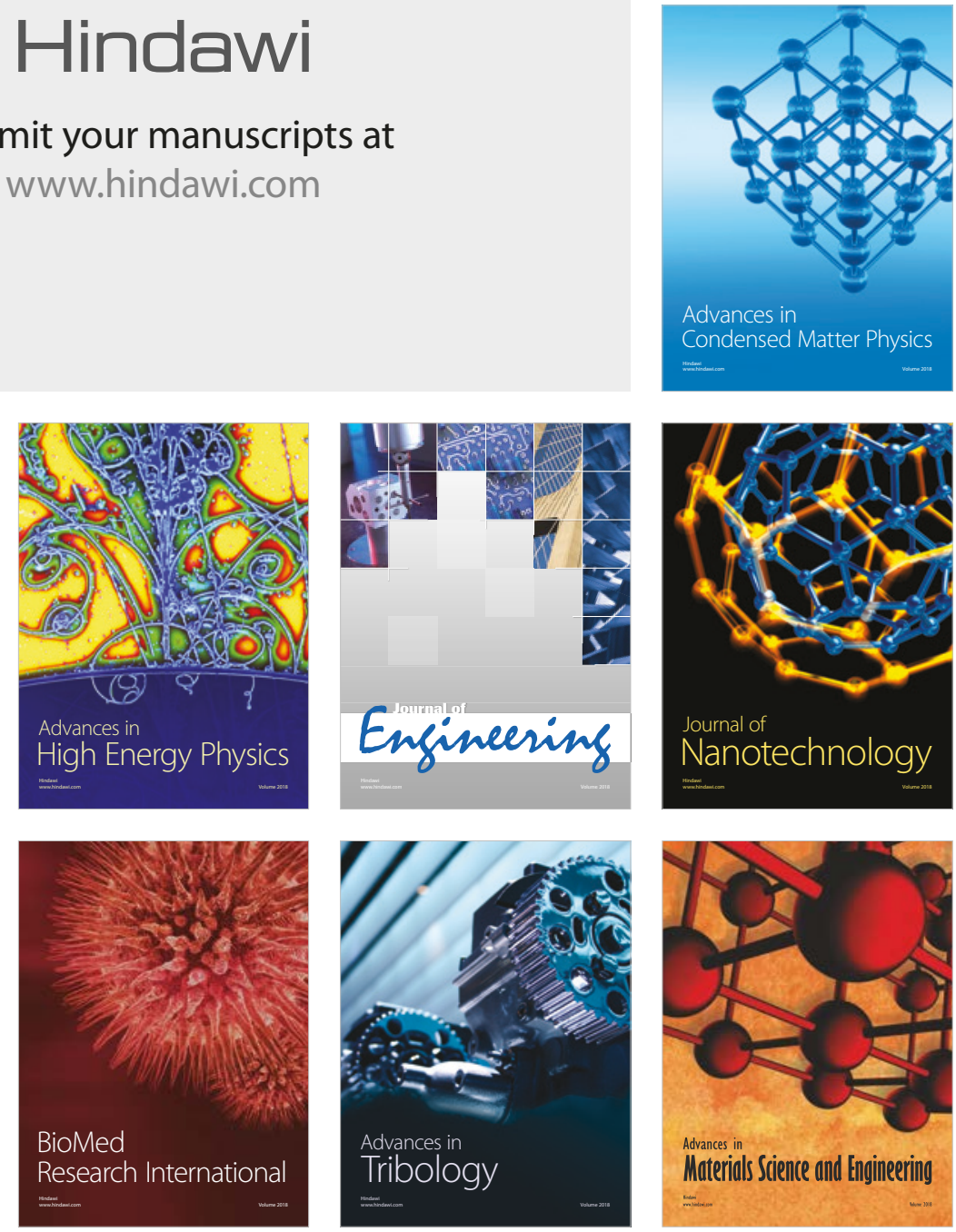